\title{
Sustained Release Bioadhesive Suppository Formulation for Systemic Delivery of Ornidazole: In-silico Docking Study
}

\author{
Rasmita Dash, Rudra Narayan Sahoo, Souvik Nandi, Rakesh Swain, Subrata Mallick* \\ Department of Pharmaceutics, School of Pharmaceutical Sciences, Siksha O Anusandhan (Deemed to be University), Bhubaneswar, \\ Odisha, INDIA.
}

\begin{abstract}
Background and Objectives: Ornidazole is widely used as an antiprotozoal and antiamoebic drug and its onset of action is within $2 \mathrm{~h}$. The major extent of the drug is metabolized in the liver and excreted in the urine and faeces. Hence, the present study of suppository formulation for sustained systemic delivery of ornidazole is significant which could minimize abdominal disturbances and nausea and delayed onset of action particularly after oral administration. Methods: Bioadhesive suppository formulations were prepared for systemic delivery of ornidazole via rectal and vaginal route. Results: The physical drug-excipient-interaction was confirmed by in-silico docking study. The affinity between drug-HPMC and drug-PEG was found to be -2 and $-0.9 \mathrm{k} \mathrm{cal} / \mathrm{mol}$ respectively. In vitro drug release of the suppositories varied depending on the viscosity grade of HPMC used and all have followed mostly diffusion controlled mechanism. The formulation containing HPMC K100 showed the most sustained release of ornidazole in both the dissolution fluid of $\mathrm{pH} 7.4$ and 4.5 (54.53 and $41.89 \%$ respectively after 360 min). Conclusion: In conclusion, present bio adhesive suppositories could be utilized for sustained systemic delivery of ornidazole via rectal and vaginal route. The findings of this work will contribute to the current knowledge and encourage future pre-clinical research.
\end{abstract}

Key words: Ornidazole, Sustained release suppository, In-silico docking, Bioadhesive formulation, in-vitro dissolution.

\section{INTRODUCTION}

Ornidazole is widely used as an antiprotozoal and anti-amoebic drug and its onset of action is within $2 \mathrm{hr}^{1}{ }^{1}$ It prevents recurrence of peptic ulcer disease caused by Helicobacter pylori. It is also used effectively and safely for the treatment of inflammatory bowel disease. ${ }^{2}$ Ornidazole is better tolerated than metronidazole; the major extent of the drug is metabolized in the liver and excreted in the urine and faeces. ${ }^{3}$ The main adverse effects of ornidazole are headache, dizziness, anorexia, intestinal spasms, loose stools etc and the very common are significant abdominal disturbances, nausea etc. ${ }^{4}$ Gastro retentive drug delivery systems were reported by increasing residence time to sustain the drug release in the g.i. tract for enhancing local action on $H$. pylori. ${ }^{5,6}$ Other route of administration like rectal or vaginal could overcome these problems. The absorption of some drugs is notable from the vaginal wall. ${ }^{7}$ Drugs used in the treatment of Trichomonas and Candida infections lead to systemic effect. ${ }^{8}$ Prostaglandins, estrogens are hormones which are rapidly and extensively absorbed through the vaginal epithelium because of its large surface area. This route bypasses first pass metabolism so the rate of absorption is high. ${ }^{9}$ Due to the mucoadhesive property it can attach to the mucus membrane of vagina and minimises the chance of detach and can sustain the drug release. Ornidazole suppository showed sustained release up to 90
Submission Date: 09-07-2019; Revision Date: 18-09-2019; Accepted Date: 17-10-2019

DOI: 10.5530/ijper.53.4s.153 Correspondence: Prof. Subrata Mallick, Department of Pharmaceutics, School of Pharmaceutical Sciences, Siksha O Anusandhan (Deemed to be University), Bhubaneswar, Odisha, INDIA. Phone: +91 6742386209 E-mail: profsmallick@gmail. com

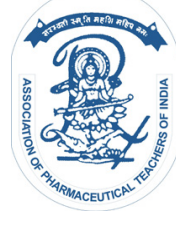

www.ijper.org 
min only as reported by Ozyazici et al..$^{10}$ The very common adverse effects of ornidazole are the significant abdominal disturbances, nausea etc. Abdominal disturbances and nausea and delayed onset of action particularly after oral administration could be minimized by using sustained and controlled release delivery of non-invasive suppository formulation of ornidazole compared to transdermal delivery. ${ }^{11}$ Hard surface of the tablets may cause irritation of the vaginal epithelium in case of intravaginal application. The slippery and smooth surface of suppositories may facilitate application and thus the irritation will be less. ${ }^{12,13}$ Therefore suppository preparations are also suitable dosage forms for vaginal administration. The HPMC is an inert and semi-synthetic polymer used to control the release rate of drug and may be used as controlled delivery component in different medicaments. ${ }^{14}$ PEG has the property of maximum water solubility. ${ }^{15}$ In this study, the rectal and vaginal suppositories were prepared using PEG 400, PEG4000, HPMC K100, HPMC K15, HPMC E5 in different ratios to sustain the release of ornidazole and compare their in vitro drug release properties.

\section{MATERIALS AND METHODS}

\section{Materials}

Ornidazole was taken as a gift sample from Jagannath Pharmaceuticals (Jagatpur, Cuttack, India). HPMC E5, HPMC K15 and HPMC K100 were purchased locally from Burgoyne and Co., Mumbai, India). PEG400 and PEG 4000 were collected from Merck Specialities Private limited, India.

\section{Preparation of suppository}

Suppository formulations were prepared by fusion molding and congealing technique. PEG 4000, PEG 400, HPMC (K15, K100, E5), ornidazole and water were used in different ratio to constitute a one-gram suppository (Table 1).
PEG 4000 and PEG 400 were taken in a $25 \mathrm{ml}$ beaker and melted at $30^{\circ} \mathrm{C}$ for 4 to $5 \mathrm{~min}$. The melted content was transferred to a china dish containing ornidazole, HPMC and water. Then the content was triturated for 4 to $5 \mathrm{~min}$ to get a uniform mixture. The china dish was kept in a hot air oven at $30^{\circ} \mathrm{C}$ for 2 to 3 min and finally the content was transferred to the suppository forming mould and preserved in refrigerator to settle down and solidification for overnight period. Next morning the solidified suppositories were removed by simply pressing in a forward direction and utilized for further testing.

\section{Differential Scanning Calorimetry (DSC)}

Thermal analysis of pure ornidazole and formulations were analysed by differential scanning calorimetry (DSC-1, Mettler Toledo software) in the range of 30 to $105^{\circ} \mathrm{C}$ at constant heating rate under liquid nitrogen gas purge.

\section{Fourier-Transform Infrared Spectroscopy (FTIR)}

Samples of pure ornidazole and prepared suppository formulations for FTIR study were placed over zinc selenide crystal and pressed on to the attenuated total reflectance crystal (ATR crystal) by using the integrated pressure application device by using Bruker infrared analyser (Bruker alpha; Ettlingen, Germany).

\section{Scanning Electron Microscopy (SEM)}

The surface morphology and crystalline nature of the samples were investigated by using Scanning Electron Microscope (ESEM-FEI Quanta-250). The drug and suppository formulations were placed over carbon tape and scanned at room temperature with voltage of $10 \mathrm{kV}$ at low vacuum $(100 \mathrm{~Pa})$.

\section{In-silico docking study}

Auto Dock Vina 1.1.2 program was used to calculate the binding between drug and polymer. The programme helps in pre-calculating the interaction between ornidazole-HPMC and Ornidazole-PEG also the binding interaction between them. Protein Data Bank (PDB)

\begin{tabular}{|c|c|c|c|c|c|c|c|}
\hline \multirow{2}{*}{$\begin{array}{c}\text { Formulation } \\
\text { codes }\end{array}$} & \multirow[t]{2}{*}{ Ornidazole (mg) } & \multirow{2}{*}{$\begin{array}{l}\text { PEG } \\
4000 \\
(\mathrm{mg})\end{array}$} & \multirow{2}{*}{$\begin{array}{c}\text { PEG } 400 \\
\text { (mg) }\end{array}$} & \multirow{2}{*}{$\begin{array}{l}\text { Water } \\
(\mathrm{ml})\end{array}$} & \multicolumn{3}{|c|}{ HPMC (mg) } \\
\hline & & & & & E5 & K15 & K100 \\
\hline ORHL5 & 200 & 320 & 400 & 0.075 & 5 & -- & -- \\
\hline ORHL10 & 200 & 325 & 400 & 0.075 & 10 & -- & -- \\
\hline ORHM5 & 200 & 320 & 400 & 0.075 & -- & 5 & -- \\
\hline ORHM10 & 200 & 325 & 400 & 0.075 & -- & 10 & -- \\
\hline ORHH5 & 200 & 320 & 400 & 0.075 & -- & -- & 5 \\
\hline ORHH10 & 200 & 325 & 400 & 0.075 & -- & -- & 10 \\
\hline
\end{tabular}


and its 3-D visualization were generated by using MGL Tools (an Auto dock tool). Marvin sketch helped in drawing the 3-D structure of (OR, HPMC, PEG). By using Auto Dock tools programme the PDBQT files of OR, HPMC, PEG were prepared. The OR was taken as ligand in opposition to the receptors like HPMC, PEG. The stability was deliberated on the basis of interaction energy between the ligand and receptor. The more negative score the better will be the binding.

\section{In vitro drug release}

The in-vitro dissolution tests of ornidazole suppositories were performed with USP dissolution apparatus (type2 , paddle type). Accurately weighed suppository samples were placed over the dialysis membrane (Dialysis Membrane- 150, LA401-30MT) (Av. Flat width-37.70 mm, Av. diameter- $25.4 \mathrm{~mm}$, Capacity approx- $5.07 \mathrm{ml} / \mathrm{cm}$, molecular weight cut-off 12000-14000, Himedia Laboratory Pvt. Ltd., Mumbai) in a both side open diffusion tube and tied with thread tightly. Diffusion tube was attached with the paddle and in vitro drug release was carried out in phosphate buffer (pH-7.4) and sodium acetate buffer (pH-4.5). ${ }^{16}$ Drug release was continued in $200 \mathrm{ml}$ medium with a rotation speed of $50 \mathrm{rpm}$ at $37^{\circ} \mathrm{C}$. Samples were withdrawn at regular time intervals and analysed in a UV spectrometer (Thermo scientific, Evolution 201-uv-visible spectrophotometer) at 319nm.

\section{RESULTS AND DISCUSSION}

Suppositories were solidified and found smoothed surface (Figure 1) and studied characterizations are described below:

\section{Differential Scanning Calorimetry (DSC)}

A sharp endothermic peak of pure ornidazole was observed at $91.26^{\circ} \mathrm{C}$ indicating pure crystalline form (Figure 2). Formulationsshowed endothermicappear-

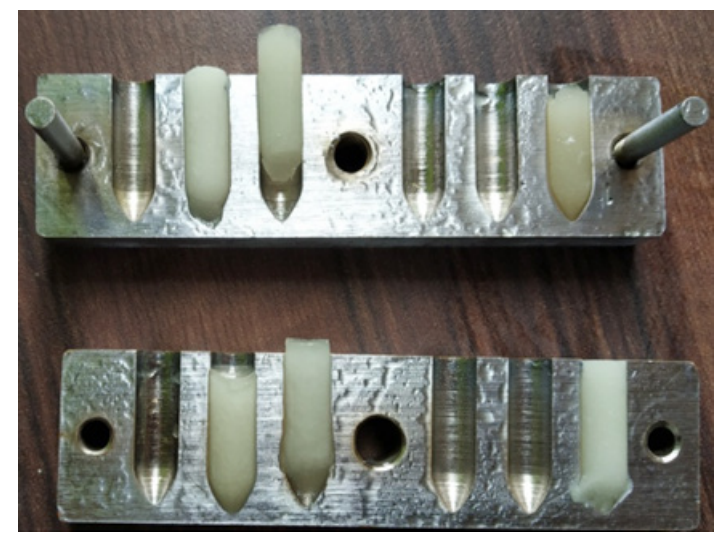

Figure 1: Prepared suppositories. ance in the range of $50-59^{\circ} \mathrm{C}$ due to presence of PEG. ${ }^{17}$ Ornidazole melting peak has been disappeared in all the formulations indicating amorphous nature of the drug in the suppositories.

\section{Fourier-Transform Infrared Spectroscopy (FTIR)}

The peaks at 3172 and $3314 \mathrm{~cm}^{-1}$ in the FTIR spectrum of ornidazole are due to the $\mathrm{C}-\mathrm{H}$ stretching and $-\mathrm{O}-\mathrm{H}$ stretching mode respectively. The peaks at $1532 \mathrm{~cm}^{-1}$ and $1365-1264 \mathrm{~cm}^{-1}$ are due to asymmetric and symmetric stretching of $\mathrm{NO}_{2}$ respectively. The $\mathrm{C}-\mathrm{O}$ stretching vibration is confirmed by the presence of peak at 1186 $\mathrm{cm}^{-1}$. The carbon connected with $\mathrm{NO}_{2}(\mathrm{C}-\mathrm{N})$ has been credited by the presence of peaks at 824 and $732 \mathrm{~cm}^{-1}$ is due to the stretching frequency of $\mathrm{C}-\mathrm{Cl}$ bond vibration. Peaks at 3500 and 3000 are due to $\mathrm{O}-\mathrm{H}$ stretching of water and $\mathrm{C}-\mathrm{H}$ stretching. Another peak at 1646 is due to $\mathrm{N}-\mathrm{H}$ bending which signifies the interaction between polymer and drug through H-bonding (Figure 3).

\section{Scanning Electron Microscopy (SEM)}

The surface morphology of the pure drug and the suppositories are shown in Figure 4. Distinct brick shaped crystals were seen in the SEM image of ornidazole. The disappearance of definite crystal geometry is seen in the SEM images of all the suppository formulations. The disappearance of crystal geometry conforms the uniform distribution of drug throughout the formulations.

\section{Analysis of molecular interaction (Docking)}

The docking scores have been cited in Table 2. In-silico study gave an idea about the interaction between drug and carrier molecule (Figure 5). The physical interaction and possible conformation were well predicted by docking study. The binding interaction in between the Ornidazole and PEG showed lowest energy as compared to OR and HPMC. The negative energy in between drug and carrier indicates stable interaction. The more

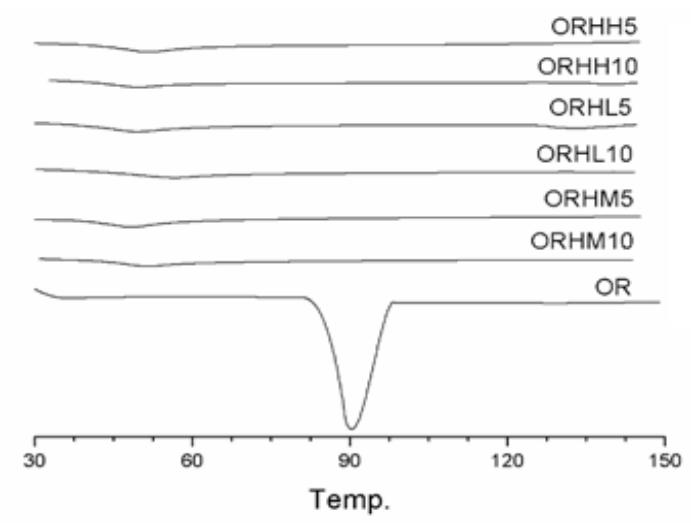

Figure 2: DSC thermo gram of ornidazole and the prepared suppositories. 


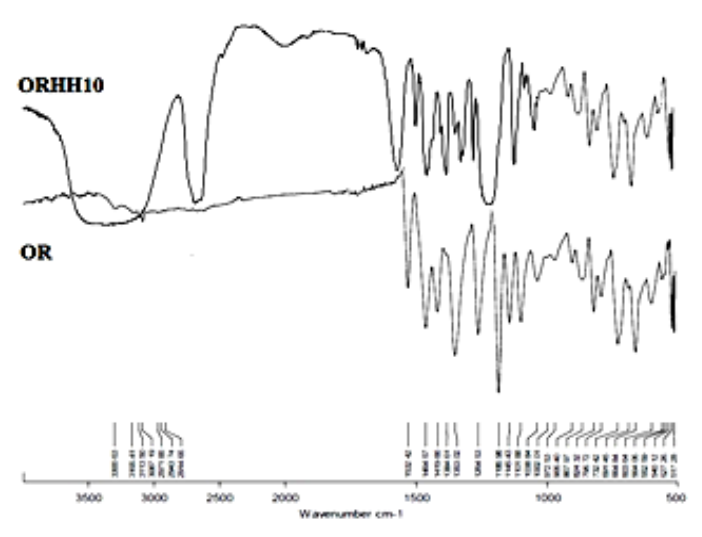

Figure 3: FTIR spectrum of OR and ORHH10.

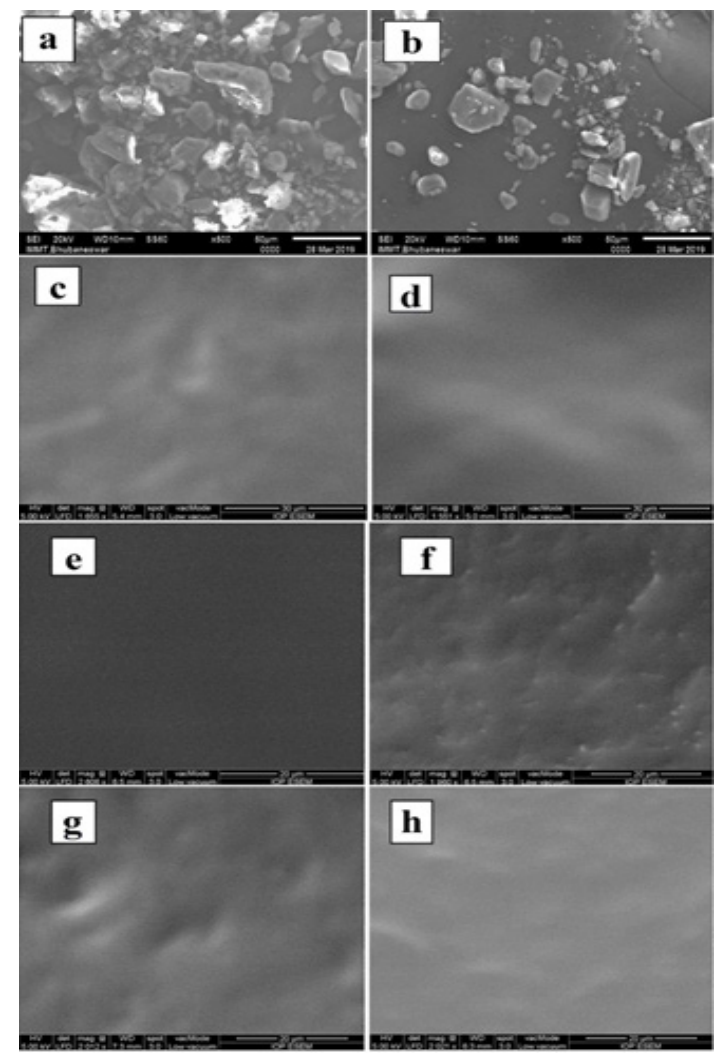

Figure 4: SEM image of pure crystalline drug ornidazole: (a) (magnification 500X), (b) (magnification 500); and suppository formulations: (c) ORHL5 (magnification 1655), (d) ORHL10 (magnification 1551); (e) ORHM5 (magnification 1551), (f) ORHM10 (magnification 1960); (g) ORHH5 (magnification 2012), (h) ORHH10 (magnification 2021).
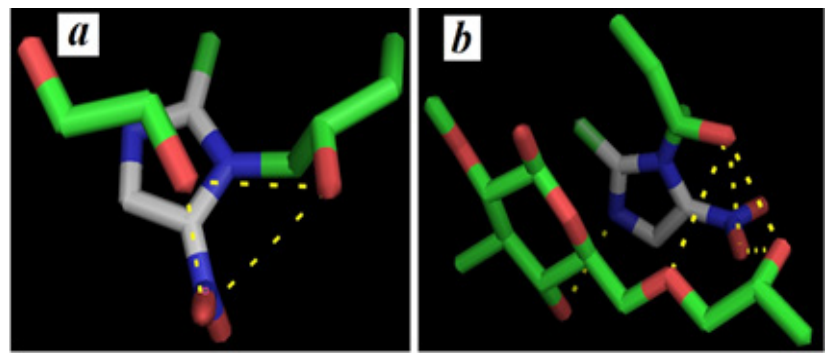

Figure 5: Docking interaction of (a) ornidazole-PEG and (b) ornidazole-HPMC.

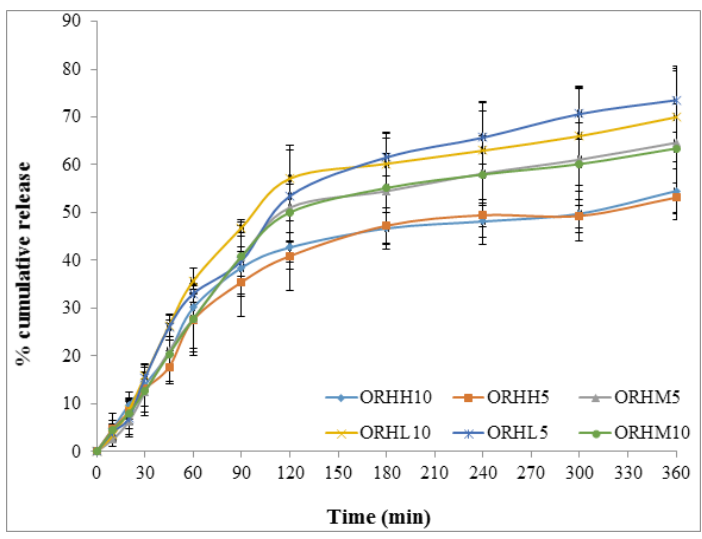

Figure 6: Ornidazole release from suppositories in phosphate buffer of pH 7.4(Results are mean \pm SD of three independent experiments, $n=3$ ).

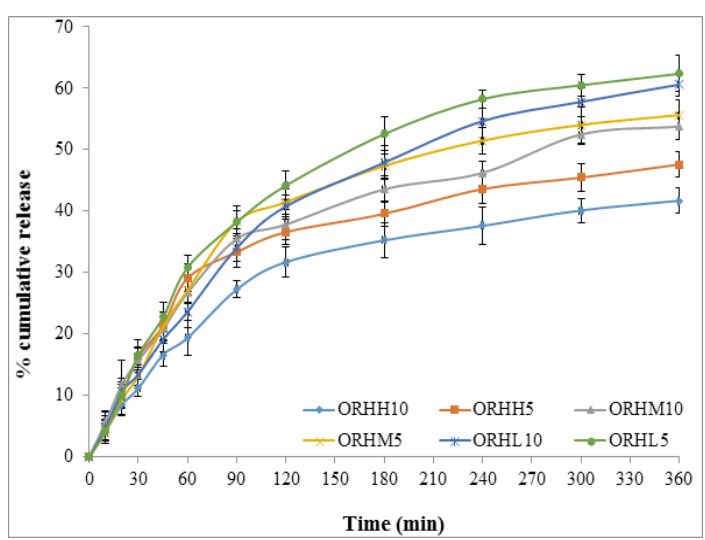

Figure 7: Ornidazole release from suppositories in phosphate buffer of $\mathrm{pH} 4.5$ (Results are mean \pm SD of three independent experiments, $n=3$ ).

Table 2: Docking score of drug and polymer interac-

\begin{tabular}{|c|c|}
\hline \multicolumn{2}{|c|}{ tion. } \\
\hline Formulation & Docking score (Affinity) \\
\hline OR-HPMC & -2.0 \\
\hline OR-PEG & -0.9 \\
\hline
\end{tabular}

negative value indicates more stable binding than that of less negative value. The binding energy values for OR-HPMC and OR-PEG were -2.0 and $-0.9 \mathrm{k} \mathrm{cal} / \mathrm{mol}$ respectively. Figure 5 shows the docking interaction of ornidazole and the polymer.

\section{In vitro drug release}

The in-vitro release of ornidazole from suppositories containing bases of different composition were analysed in different time intervals. As shown in the Figure 6 and Figure 7 the diffusion of ornidazole from suppositories were in a sustained manner and continued to $6 \mathrm{~h}$ to release about $50-70 \%$. Ornidazole release pattern from the suppositories were in the order of ORHH1 0>ORHH5>ORHM10>ORHM5>ORHL10>ORHL5. 


\begin{tabular}{|c|c|c|c|c|c|c|c|c|c|}
\hline \multirow{2}{*}{$\begin{array}{l}\text { Formulation } \\
\text { code }\end{array}$} & \multicolumn{2}{|c|}{ Zero order } & \multicolumn{2}{|c|}{ First order } & \multicolumn{2}{|c|}{ Higuchi } & \multicolumn{3}{|c|}{ Korsmeyer-Peppas } \\
\hline & $\mathrm{K}_{0}\left(\% \cdot \mathrm{min}^{-1}\right)$ & $r^{2}$ & $K_{F}\left(\min ^{-1}\right)$ & $r^{2}$ & $K_{H}\left(\% \cdot \min ^{-1 / 2}\right)$ & $r^{2}$ & $\mathbf{n}$ & Kp & $r^{2}$ \\
\hline ORHL5 & 0.207 & 0.859 & 1.955 & 0.946 & 4.739 & 0.959 & 0.787 & 0.012 & 0.950 \\
\hline ORHL10 & 0.191 & 0.791 & 1.935 & 0.881 & 2.205 & 0.926 & 0.757 & 0.002 & 0.973 \\
\hline ORHM5 & 0.182 & 0.825 & 1.953 & 0.896 & 4.337 & 0.938 & 0.797 & 0.099 & 0.946 \\
\hline ORHM10 & 0.178 & 0.824 & 1.949 & 0.890 & 0.343 & 0.939 & 0.790 & 0.024 & 0.965 \\
\hline ORHH5 & 0.143 & 0.806 & 1.948 & 0.859 & 1.073 & 0.937 & 0.711 & 0.039 & 0.972 \\
\hline ORHH10 & 0.140 & 0.782 & 1.940 & 0.844 & 0.342 & 0.927 & 0.705 & 0.072 & 0.964 \\
\hline
\end{tabular}

\begin{tabular}{|c|c|c|c|c|c|c|c|c|c|}
\hline \multirow{2}{*}{$\begin{array}{l}\text { Formulation } \\
\text { code }\end{array}$} & \multicolumn{2}{|c|}{ Zero order } & \multicolumn{2}{|c|}{ First order } & \multicolumn{2}{|c|}{ Higuchi } & \multicolumn{3}{|c|}{ Korsmeyer-Peppas } \\
\hline & $\mathrm{K}_{0}\left(\% \cdot \mathrm{min}^{-1}\right)$ & $r^{2}$ & $K_{F}\left(\min ^{-1}\right)$ & $\mathbf{r}^{2}$ & $K_{H}\left(\% \cdot \min ^{-1 / 2}\right)$ & $r^{2}$ & $\mathbf{n}$ & $\mathrm{Kp}$ & $r^{2}$ \\
\hline ORHL5 & 0.171 & 0.848 & 1.947 & 0.920 & 1.932 & 0.964 & 0.741 & 0.038 & 0.969 \\
\hline ORHL10 & 0.161 & 0.893 & 1.960 & 0.950 & 3.352 & 0.979 & 0.723 & 0.037 & 0.986 \\
\hline ORHM5 & 0.151 & 0.822 & 1.947 & 0.885 & 1.316 & 0.949 & 0.726 & 0.027 & 0.968 \\
\hline ORHM10 & 0.139 & 0.845 & 1.946 & 0.908 & 0.351 & 0.969 & 0.681 & 0.116 & 0.970 \\
\hline ORHH5 & 0.119 & 0.778 & 1.940 & 0.839 & 1.927 & 0.934 & 0.672 & 0.105 & 0.954 \\
\hline ORHH10 & 0.110 & 0.832 & 1.958 & 0.874 & 0.167 & 0.959 & 0.659 & 0.049 & 0.977 \\
\hline
\end{tabular}

The in-vitro release of ornidazole from suppository containing 10mg of HPMC K100 (ORHH10) showed the most sustained release as compare to all the formulation. ${ }^{18}$ The drug release up to 360 min was considered as the main criterion for understanding the most sustaining effect. Drug release kinetics was not considered as the criterion for understanding the most sustaining effect. Suppository ORHH10 exhibited $41.68 \%$ drug release whereas; ORHM10 has shown $53.75 \%$ up to $360 \mathrm{~min}$.

\section{Kinetics of drug release}

Drug release mechanism has been predicted to develop a rational formulation utilizing mathematical models. Different kinetic models like Zero order, First order, Higuchi and Korsmeyer-Peppas model ${ }^{19-31}$ were used to describe the kinetics of ornidazole release of suppository. The model that uses highest level of correlation $\left(r^{2}\right)$ was used as the model-fitting kinetics. These models are represented as follows:

Zero order model: $Q=Q_{0}+K_{0} t$

First order model: $\log (100-Q)=\frac{K_{F} . t}{2.303}$

Higuchi model: $Q=K_{H} \times \sqrt{t}$

Korsmeyer-Peppas model: $Q=K_{p} \times t^{n}$

$\log Q=\log K_{P}+n$.Logt $------(i v)$

$Q=$ Cumulative percent drug release at time $t$

$Q_{0}=$ Cumulative percent drug release at time $t=0$

$K_{0}=$ Zero order release rate constant

$K_{\mathrm{F}}=$ First order release rate constant

$K_{H}=$ Higuchi release rate constant,
$K_{p}=$ Peppas release rate constant or, Parameter reflecting the structural and geometric characteristics of the delivery device,

$n=$ Power law exponent, or release exponent.

The kinetic parameters as per model are presented in the Table 3 and Table 4. Result indicates that the release kinetics of all the suppository formulations $(\mathrm{pH} 7.4$ and $\mathrm{pH} 4.5)$ is mostly following the Korsmeyer-Peppas model because of higher $r^{2}$ value (0.946-0.986) compare to other models. The release exponent values $(n=0.659$ 0.797 ) are a sign of partially diffusion controlled and partially erosion controlled release. Fitting of release data with Higuchi model has shown $r^{2}$ values (0.9260.929) closer to Korsmeyer-Peppas model indicating also diffusion controlled release to some extent.

\section{CONCLUSION}

The drug and polymer showed a significant interaction between them which was conformed from FTIR study and was supported by molecular level study (in-silico docking). The in-vitro release of ornidazole from suppository containing 10mg of HPMC K100 (ORHH10) showed the most sustained release as compare to all the formulation. Due to the presence of HPMC, it works as mucoadhesive so that it can attach to the mucus membrane of vagina and rectus for longer period of time. So this can be an approach in sustaining the release of ornidazole up to $6 \mathrm{hr}$ and minimises the repeating of dose. 


\section{ACKNOWLEDGEMENT}

The authors are grateful to Prof. (Dr) Monojranjan Nayak, President, Siksha 'O' Anusandhan (Deemed to be University) for financial support and laboratory facility. We are also grateful to receive Ornidazole as gift sample from Jagannath Pharmaceuticals, Cuttack, Odisha.

\section{CONFLICT OF INTEREST}

The authors declare no conflict of interest.

\section{ABBREVIATIONS}

HPMC: Hydroxy Propyl Methyl Cellulose; PEG: Poly Ethylene Glycol; SD: Standard Deviation.

\section{REFERENCES}

1. https://www.medicineindia.org/pharmacology-for-generic/474/ornidazole.

2. Triantafillidis JK, Antoniou A, Emmanoulidis A, Nicolakis D, Barbatzas C, Cheracakis $\mathrm{P}$. Ornidazole in the prevention of recurrence of crohn's disease. Ital J Gastroenterol. 1998;30(4):446-47.

3. Taburet AM, Delion F, Attali P, Thebault JJ, Singlas E. Pharmacokinetics of ornidazole in patients with severe liver cirrhosis. Clin Pharmacol Ther 1986;40(3):359-64.

4. https://www.lybrate.com/medicine/ornidazole/health-feed/questions.

5. Mallick S, Pattnaik S, Swain K, De PK, Saha A, Mazumdar P, et al. Physicochemical characterization of interaction of ibuprofen by solid-state milling with aluminum hydroxide. Drug Dev Ind Pharm. 2008;34(7):726-34.

6. Swain RP, Nagamani A, Shankar PU. Formulation and evaluation of gastrobilayer floating tablets of ezetimibe as immediate release layer and atenolol as sustained release layer. Indian J Pharm Edu Res. 2019;53(2):S93-103.

7. Baloḡlu E, Özyazıcı M, Baloḡlu A, Ova L. A randomized controlled trial of a new ovule formulation of ornidazole for the treatment of bacterial vaginosis. Clin Pharm Ther. 2003;28(2):131-6.

8. Reddy RS, Kumar L, Pydi CR, Reddy MS, Verma R. Development of fluconazole suppositories for the treatment of candida infection of genitourinary tract. Indian J Pharm Edu Res. 2018;52(4):S16-22.Baria AH, Patel RP, Suthar AM, Parmar RB. Formulation development and evaluation of sustained release aceclofenac suppository. Int J Pharm Sci. 2009;1(2):71-3.

9. Ozyazici M, Gokçe E, Hizarcioglu SY, Taner MS, Koseoglu K, Ertan G. Dissolution and vaginal absorption characteristics of metronidazole and ornidazole. Pharmazie. 2006;61(10):855-61.

10. Fuh YM, Pham DC, Weng CF. Effects of sting plant extracts as penetration enhancers on transdermal delivery of hypoglycemic compounds. Medicina. 2019;55(5):121.

11. Havaldar VD, Yadav AV, Dias RJ, Mali KK, Kale SS, Pujari PP. Rectal suppository of mucoadhesive microspheres of alverine citrate for irritable bowel disease: In vitro evaluation. Res J Pharm Technol. 2018;11(7):3091-8.

12. Mallick S, Dey PK, Sannigrahi S, Mitra A. Crystallization of a non-steroidal anti-inflammatory drug from ethanol-water solution in presence of polymers: Physicochemical characterization and release behaviour from suppositories. Acta Pol Pharm. 2004;61:447-53.
13. Nanda A, Sahoo RN, Pramanik A, Mohapatra R, Pradhan SK, Thirumurugan $A$, et al. Drug-in-mucoadhesive type film for ocular anti-inflammatory potential of amlodipine: Effect of sulphobutyl-ether-beta-cyclodextrin on permeation and molecular docking characterization. Colloids Surf B. 2018;172:555-64.

14. Allen C, Santos ND, Gallagher R, Chiu GNC, Shu Y, Li WM, et al. Controlling the physical behavior and biological performance of liposome formulations through use of surface grafted poly (ethylene glycol). Biosci Rep. 2002;22(2):225-50.

15. Gomaa E, Abu LAS, Hasan AA, Ghazy FES. Preparation and characterization of intravaginal vardenafil suppositories targeting a complementary treatment to boost in vitro fertilization process. Eur J Pharm Sci. 2018;111:113-20.

16. Das D, Ganguli AK. Design of nanostructured cadmium tantalate and niobate and their photocatalytic properties. RSC Adv. 2013;3(44):21697-705.

17. Kumar DV, Swetha P, Prasad GS, Kumar AA. Assay method development and validation for simultaneous quantitative estimation of diloxanide furoate and ornidazole in tablets by RP-HPLC. Int J Pharm Pharm Sci. 2015;7(10):35762.

18. Mallick S, Pattnaik S, Swain K, De PK. Current perspectives of solubilization: Potential for improved bioavailability. Drug Dev Ind Pharm. 2007;33(8):86573.

19. Mallick S, Pattnaik S, Swain K, De PK, Saha A, Mazumdar P, et al. Physicochemical characterization of interaction of ibuprofen by solid-state milling with aluminum hydroxide. Drug Dev Ind Pharm. 2008;34(7):726-34.

20. Mallick S, Sahu A, Pal K. Dissolution behaviour of nalidixic acid solid dispersions using water soluble dispersion carriers. Acta Pol Pharm. 2004;61(1):21-30.

21. Bhandari MS, Wairkar SM, Patil US, Jadhav NR. Co-amorphization of ibuprofen by paracetamol for improved processability, solubility and in vitro dissolution. Acta Chim Slov. 2018;65(3):492-501.

22. Mohapatra R, Mallick S, Nanda A, Sahoo RN, Pramanik A, Bose A, et al. Analysis of steady state and non-steady state corneal permeation of diclofenac. RSC Adv. 2016;6(38):31976-87.

23. Mallick S, Pradhan SK, Mohapatra R. Effects of microcrystalline cellulose based comilled powder on the compression and dissolution of ibuprofen. Int $\mathrm{J}$ Biol Macromol 2013;60:148-55.

24. Panda B, Parihar AS, Mallick S. Effect of plasticizer on drug crystallinity of hydroxypropyl methylcellulose matrix film. Int J Biol Macromol. 2014;67:295302.

25. Mallick S, Pradhan SK, Chandran M, Acharya M, Digdarsini T, Mohapatra R. Study of particle rearrangement, compression behaviour and dissolution properties after melt dispersion of ibuprofen, avicel and aerosil. Results Pharm Sci. 2011;1(1):1-10.

26. Mallick S, Roy K, Chakraborty A, Saha S. Mechanism of in vitro release kinetics of flurbiprofen loaded ethylcellulose micropellets. Acta Pol Pharm. 2002;59:193-98.

27. Mallick S, Gupta BK, Ghosal SK. Development and characterization of release profile of nifedipine as an effective controlled release system. J Sci Ind Res. 1999;58(12):1010-16.

28. Dvockova K, Kaledaite R, Gajdziok J, Rabiskova M, Bajerova M, MuselikJ, et al. The development of Eudragit ${ }^{\circledR}$ NM-based controlled-release matrix tablets. Medicina. 2012;48(4):192-202.

29. Kumar L, Reddy MS, Shirodkar RK, Pai GK, Krishna VT, Verma R. Preparation and characterization of fluconazole vaginal films for the treatment of vaginal candidiasis. Indian J Pharm Sci. 2013;75(5):585-90.

30. Pramanik A, Sahoo RN, Nanda A, Mohapatra R, Singh R, Mallick S. Ocular Permeation and Sustained Antiinflammatory Activity of Dexamethasone from Kaolin Nanodispersion Hydrogel System. Curr Eye Res. 2018;43(6):828-38. 

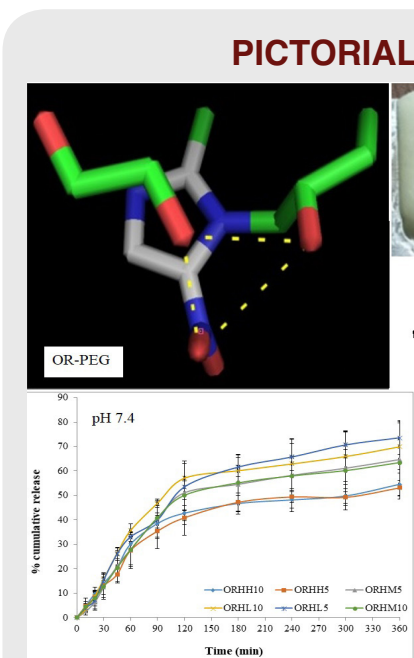

Time (min)
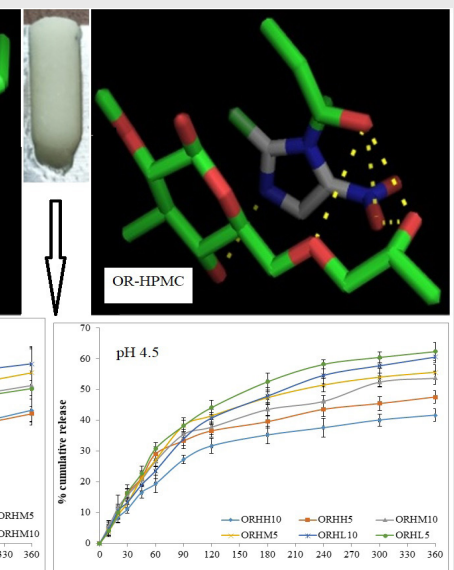

Time (min)

\section{SUMMARY}

- Sustained release ornidazole suppositories were prepared for systemic delivery to avoid abdominal disturbances and delayed onset of action after oral administration.

- In silico docking study revealed the affinity between ornidazole-HPMC and ornidazole-PEG of -2 and $-0.9 \mathrm{k} \mathrm{cal} / \mathrm{mol}$ respectively.

- Suppository (HPMC K100) showed the most sustained diffusion controlled release of ornidazole at $\mathrm{pH} 7.4$ and 4.5 .

- Bioadhesive suppositories could be conveniently utilized for sustained systemic delivery via rectal and vaginal route for more than $6 \mathrm{hr}$.

\section{About Authors}

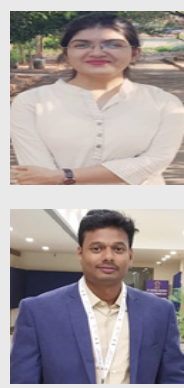

Rasmita Dash, M.Pharm from School of Pharmaceutical Sciences, Siksha O Anusandhan (Deemed to be University), Bhubaneswar, Odisha, India.

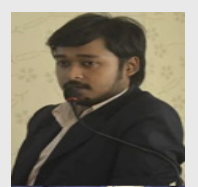

Rudra Narayan Sahoo, M.Pharm, currently engaged as an INSPIRE Fellow under DST Government of India at School of Pharmaceutical Sciences, Siksha 'O' Anusandhan (Deemed to be University), Bhubaneswar, Odisha, India. His research area of interest is Formulation and Development, and Drug Delivery Systems.

Souvik Nandi, M.Pharm, currently engaged as a junior research fellow at School of Pharmaceutical Sciences, Siksha ' $O$ ' Anusandhan (Deemed to be University), Bhubaneswar, Odisha, India. His research area of interest is Formulation and Development, and Novel Drug Delivery Systems.

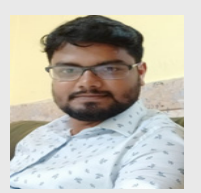

Rakesh Swain, M.Pharm, currently engaged as a junior research fellow at School of Pharmaceutical Sciences, Siksha 'O' Anusandhan (Deemed to be University), Bhubaneswar, Odisha, India

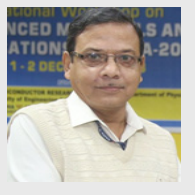

Subrata Mallick, (M.Pharm, PhD, PGDBM, FIC) is a life member of Association of Pharmaceutical Teachers of India, and Indian Pharmaceutical Association. At present he is the Professor and Heading the Department of Pharmaceutics, School of Pharmaceutical Sciences, Siksha'O' Anusandhan (Deemed to be University), Bhubaneswar, India. He is the reviewer of Elsevier, Wiley, Informa Healthcare, Taylor and Francis, Bentham Science, Springer, IEEE Xplore, Dovepressetc. and editorial board member of several International Journals of America, Canada, UK, Thailand, India etc. He is also aMember of doctoral committee of several universities. His current research areas of interest are: Ocular Drug Delivery Systems, Drug Stabilisation and Kinetics, Mucosal Delivey, Powder Compaction etc. More than 160 number of full research papers and conference proceedings are published in International and National levels under his guidance.

Cite this article: Dash R, Sahoo RN, Nandi S, Swain R, Mallick S. Sustained Release Bioadhesive Suppository Formulation for Systemic Delivery of Ornidazole: In-silico Docking Study. Indian J of Pharmaceutical Education and Research. 2019;53(4s):s580-s586. 